\title{
Evolution of the korA-oriV segment of promiscuous IncP plasmids
}

\author{
Christopher M. Thomas, Christopher A. Smith, $\dagger$ John P. Ibbotson, $\ddagger$ \\ Lynda Johnston§ and Naijin Wang\|
}

Author for correspondence: Christopher M. Thomas. Tel: +44121 414 5903. Fax: +441214145925.

1 School of Biological Sciences, University of Birmingham, Edgbaston, Birmingham B15 2TT, UK
Plasmids belonging to Escherichia coli incompatibility group $P$ are of particular interest because they can transfer between, and be stably maintained in, almost all Gram-negative bacterial species. The segment of the IncP $\alpha$ plasmid genome between the key regulatory gene korA and the vegetative replication origin, oriV, encodes a series of operons co-regulated with replication and transfer functions by the KorA protein. To determine which of these genes are fikely to have an important role in IncP plasmid survival the equivalent region of the distantly related IncP $\beta$ plasmid R751 was sequenced. Sequence comparisons show that the kla operon (formerly the kilA locus, which is also responsible for a cryptic tellurite-resistance determinant) is completely absent from R751. Similarly in the kle region, which encodes genes associated with the KilE+ phenotype of unknown function, $k / e C$ and $k / e D$, which we proposed arose by a duplication of $k l e A$ and $k / e B$, are also completely absent. The genes that are conserved are KICA (formerly kilC, responsible for the KilC', and recently proposed to be involved in overcoming restriction barriers during transfer), kICB (an ORF interrupted by Tn1 insertion in RK2), korC (a transcriptional repressor which controls the $k / c K$ and $k / e$ operons), and kleA, $k l e B, k l e E$ and $k l e F$. A striking feature of the organization in R751 is the lack of the strong transcriptional termination signals which are present in IncP $\alpha$ plasmids. The degree of divergence between the plasmids facilitates the identification of motifs of probable functional importance in the primary protein sequences.

Keywords: broad-host-range plasmid, plasmid R751, genome evolution, plasmid maintenance, antirestriction

\section{INTRODUCTION}

Considerable attention has been focused on plasmids belonging to Escherichia coli incompatibility group $\mathrm{P}$ because of their ability to transfer between, and maintain themselves stably in, diverse species of Gram-negative

\footnotetext{
†Present address: Department of Biological Sciences, Keele University, Keele, Staffordshire ST5 5BG, UK.

¥Present address: Department of Infection, University of Birmingham Medical School, Edgbaston, Birmingham B15 2TT, UK.

SPresent address: Promega, Delta House, Enterprise Road, Chilworth Research Centre, Southampton SO1 7NS, UK.

|| Present address: Department of Biochemistry and Physiology, University of Reading, Whiteknights, Reading RG6 2AJ, UK.

The GenBank accession numbers for the sequences reported in this paper are 008908 (R751 korA-oriM. L13392 (RK2 oriV-k/CB) and L13287 (RK2 kleE-klaA).
}

bacteria (for a review see Thomas \& Smith, 1987). Most plasmids of this group fall into one of two subfamilies, IncP $\alpha$ or IncP $\beta$. The best-studied IncP $\alpha$ plasmids form an indistinguishable group of plasmids, RK2, RP1, RP4, R68 and R18 (Pansegrau et al., 1994) (Fig. 1). In this paper, the names RK2 and RP4 will be used because the Inc $\mathrm{P} \alpha$ segments studied have been derived from both isolates. Detailed molecular genetic analysis of RK2 and RP4 has defined the blocks of genes required for vegetative replication and conjugative transfer as well as the genes involved in segregational stability (Thomas \& Helinski, 1989; Guiney \& Lanka, 1989; Pansegrau et al., 1994). For vegetative replication the plasmid requires ori V, the replication origin (Figurski \& Helinski, 1979; Thomas et al., 1980; Stalker et al., 1981), and $\operatorname{trf} A$, which encodes the initiator protein, TrfA (Figurski \& Helinski, 1979; Thomas et al., 1980; Shingler \& Thomas, 1984a; Smith \& Thomas, 1984). For conjugative transfer the 
plasmid requires oriT, the transfer origin (Guiney \& Helinski, 1979; Guiney \& Jakobson, 1983; Pansegrau et al., 1990), as well as proteins encoded in the $\operatorname{traJ-\operatorname {tra}A}$ operon (Lessl et al., 1993), the traK-traM operon (Guiney et al., 1989) and the trb operon (Lessl et al., 1992).

A unique feature of the IncP plasmid organization is the coordinated expression of these genes for replication and transfer that is mediated by regulatory proteins encoded in the central control operon (kor $A B F$ ) (MotallebiVeshareh et al., 1992; Thomson et al., 1993) (Fig.1). The product of kor $B$ is known to repress transcription of both the $\operatorname{trf} A$ and $\operatorname{trb}$ operons (Shingler \& Thomas, 1984b; Motallebi-Veshareh et al., 1992; Thomson et al., 1993; Williams et al., 1993), while multiple binding sites for KorB are found in both the tra and trb regions (Balzer et al., 1992), although whether KorB modulates gene expression when it binds at these points is unknown.

The kor $A$ gene product also acts at many points, but all of these are known promoter regions. Some of these regions coincide with promoters repressed by $\operatorname{KorB}$ (kor $A p$, $k f r A p$, kil $A p$ and $\operatorname{trf} A p$ ) (Shingler \& Thomas, 1984b; Smith et al., 1984; Schreiner et al., 1985; Young et al., 1985, 1987; Theophilus et al., 1985; Thomas et al., 1990). At the face-to-face divergent promoters $\operatorname{trf} A p$ and $\operatorname{tr} b A p$, Kor $A$ acts both negatively and positively, repressing $\operatorname{trf} A p$ and simultaneously derepressing $\operatorname{trb} A p$ (JaguraBurdzy \& Thomas, 1994). The other promoters under KorA control are repressed by a third repressor, KorC, but not KorB (kcr Ap, kcrBp and kilCp) (Thomas et al., 1988; Kornacki et al., 1990, 1993). It has been suggested that the products of the operons which are co-regulated with replication and transfer functions, but do not encode genes essential for either of these processes, are likely to play an auxiliary role in plasmid maintenance and propagation (Figurski et al., 1982; Larsen et al., 1994). Although no clear role has yet been established for stability systems, the IncP plasmids appear to have systems which have not yet been mapped to specific loci and may turn out to be encoded by these 'cryptic' operons (Harayama et al., 1980; Jovanovic et al., 1994).

One way of testing this hypothesis is to exploit the fact that the IncP family has two branches which have undergone considerable divergence from their common ancestor but have retained many fundamental replication, transfer and control functions intact (Lanka et al., 1985; Meyer \& Shapiro, 1980; Figurski et al., 1982; Villaroel et al., 1983; Chikami et al., 1985; Yakobson \& Guiney, 1983). The best-studied IncP $\beta$ plasmid is R751 (Jobanputra \& Datta, 1974) (Fig. 1). Sequence comparisons have already shown that considerable drift has occurred where the sequences are under less constraint (Smith \& Thomas, 1985; Furste et al., 1989; Miele et al., 1991; Waters et al., 1992; Ziegelin et al., 1991). Therefore, conservation of function between IncP $\alpha$ and $\operatorname{IncP} \beta$ plasmids indicates that the gene provides a selective advantage for the plasmid. In this paper we present a comparison of the plasmid sector between kor $A$ and ori $V$. The results allow identification of the 'core' functions in this region which are present in both IncP subfamilies.

\section{METHODS}

DNA manipulations and sequencing. Plasmid DNA was isolated from E. coli $\mathrm{C} 600$ by the method of Birnboim \& Doly (1979) for small-scale preparation and by a modified version of this method for large-scale preparation (Smith \& Thomas, 1983). Manipulation and analysis of DNA was essentially as described by Maniatis et al. (1982). DNA sequencing was carried out by the method of Maxam \& Gilbert (1980), with minor modifications (Smith \& Thomas, 1987), and by chaintermination (Sanger et al., 1977), using either a Sequenase 2 kit from USB or ABI kit with dye-terminators, followed by analysis on an ABI $373 \mathrm{~A}$ automated DNA sequencer. Computer manipulations of the DNA sequence were carried out using the University of Wisconsin GCG package (Devereux et al., 1984).

\section{RESULTS AND DISCUSSION}

\section{The korA-oriV segment of $\mathbf{R 7 5 1}$ is shorter than that of RK2}

We previously cloned the $9.8 \mathrm{~kb}$ Sall fragment of R751 running from coordinates 0 to 10 on the standard map (Fig. 1). We subcloned ori $V$ from this and determined its DNA sequence (Smith \& Thomas, 1985). Subsequently we have sequenced almost all of this Sall fragment. The segment which is the subject of this paper (GenBank accession number U08908) was located by identifying the position of the regulatory gene kor $A$ by searching for homology to the RK2 kor $A$ gene. The assumption that there would be a kor $A$ gene was based on the observation that R751 is phenotypically KorA ${ }^{+}$(Figurski et al., 1982). kor $A$ was located easily using the program GAP (Devereux et al., 1984). By using ori $V$ and kor $A$ as reference points we were able to determine that the distance between them is $4.3 \mathrm{~kb}$. This contrasts with a distance of $12.7 \mathrm{~kb}$ for RK2 or $7.7 \mathrm{~kb}$ when $\operatorname{Tn} 1$ is excluded. Clearly there are additional sequences in this segment of RK2 which are not present in R751.

\section{Alignment of R751 and RK2 sequences between korA and oriv}

To compare R751 with RK2, the ori $V$-kor $A$ region of RK2 excluding $\operatorname{Tn} 1$ was sequenced. Our sequencing of parts of this region has been reported previously (Thomas et al., 1988; Walter et al., 1991), while the intervening regions have been deposited in the databases (oriV-Tn1, L13392; kle A-klaA, L13287), except for the Tn1-korC region, which had been published by others (M32794; Kornacki et al., 1990). The kle A-kleF, kla $A-k l a C$ and klc $A$ regions have also been sequenced (Kornacki et al., 1993; Goncharoff et al., 1991; Larsen \& Figurski, 1994). Inspection of the RK2 DNA sequence on either side of the $\operatorname{Tn} 1$ insertion reveals a 5 bp duplication (TTTTA), which strongly indicates that there is a simple insertion with no associated deletions or rearrangements. This is confirmed by the comparison with R751, whereby the R751 sequences which line up with the RK2 sequence on either side of the $\operatorname{Tn} 1$ insertion are contiguous and show no evidence of loss of DNA from RK2 (data not shown). Comparison of the ori $V-k o r A$ regions by a dotplot allowed us to locate regions of high conservation between 


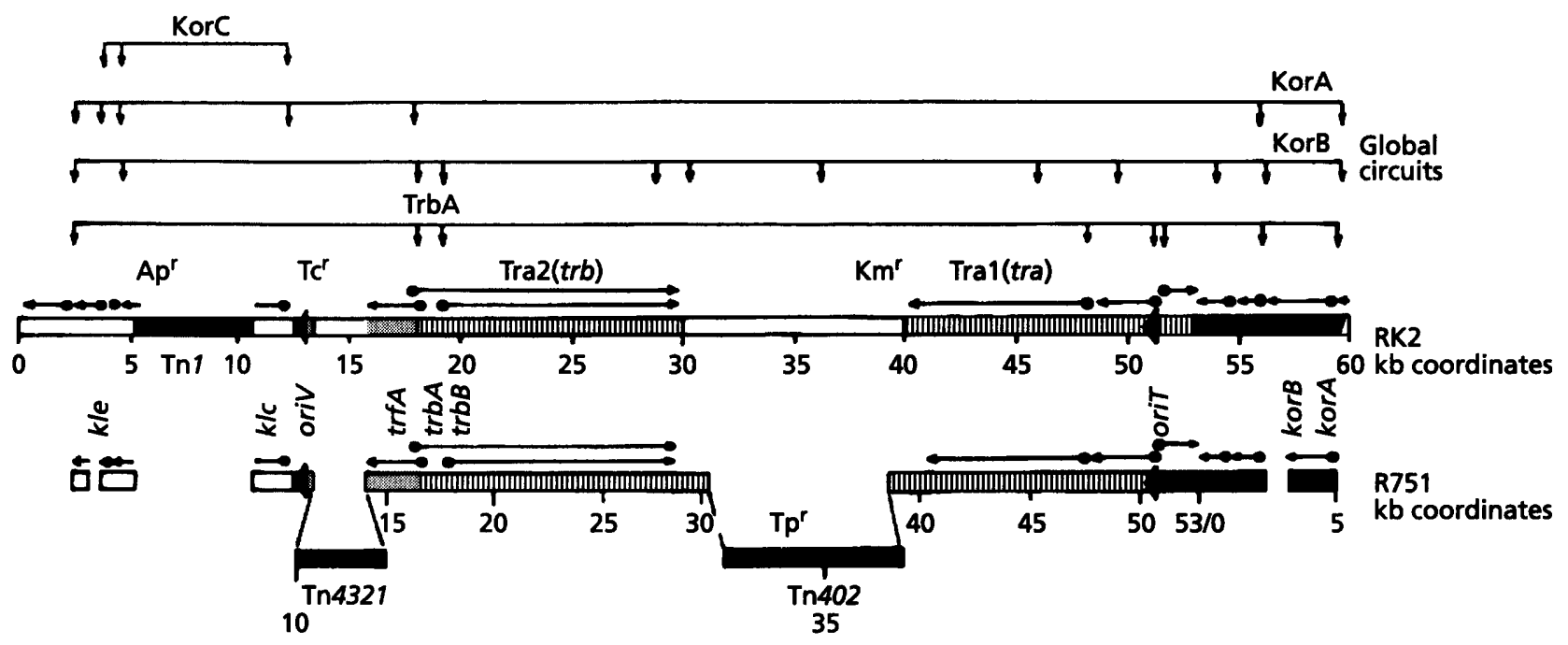

Fig. 1. Maps of RK2 and R751 showing the global regulatory circuits already established for RK2. The basis for the physical and genetic map of RK2 is given by Pansegrau et al. (1994). The alignment of RK2 and R751 is based on previous studies (Smith \& Thomas, 1985, 1987; Smith et al., 1993; Pansegrau \& Lanka, 1987; Miele et al., 1991; Waters et al., 1992; Furste et al., 1989; Ziegelin et al., 1991); this work and unpublished data from this laboratory (C.M.T., Peter Thorsted, Chris Yates, Alex Foster and L.J.). Genes of known function are indicated as follows: replication, 國; transfer, 四; control, 口.

$\mathrm{R} 751$ and RK2 (Fig. 2). It is clear from these results that $\operatorname{klc} A, \operatorname{klcB}, \operatorname{kor} C, k l e A(k c r A 1)$, kleB (kcr $A 2), k l e E, k l e F$ and $k o r A$ are highly conserved genes. $k l c A$ and $k l c B$ are in the operon responsible for the $\mathrm{KilC}^{+}$phenotype (Figurski et al., 1982; Larsen \& Figurski, 1994), which is expressed in the absence of korC (KilC override). kle genes belong to the region associated with the $\mathrm{KilE}^{+}$phenotype (Young et al., 1987). Analysis of the DNA sequence with the program CODONPREFERENCE showed that all the new ORFs identified in this segment of R751 conformed to the pattern of codon usage expected from known functional ORFs in RK2/RP4.

\section{Major deletions/insertions}

A number of gaps or insertions are revealed by the alignment of RK2 and R751 sequences in the ori $V$-kor $A$ region. First, there is an extra 600 bp upstream of klc $A$ in R751 which has no significant sequence identity to the equivalent region of RK2 (Fig. 2a). Secondly, sequence similarity between $\mathrm{R} 751$ and RK2 disappears immediately after the end of $k \operatorname{lc} A$ and does not reappear until about 400 bp later, relative to the RK2 sequence. On R751 the gap is only about 100 bp. In both RK2 and R751 there appears to be a long ORF which occupies the whole klc $A$-kor $C$ gap. However, this would have been distupted in RK2 by the insertion of Tn1, which might have removed the constraint to maintain the integrity of this gene, allowing the drift which is observed in RK2 (Fig. 2a). Thirdly, there is a break in the diagonal where kleC and $k l e D$ are in RK2 (Fig. 2b), consistent with the proposal that the kle $A / B$ and $k l e C / D$ operons in RK2 arose by duplication (Thomas et al., 1988). There is a second diagonal displaced to the right that shows kle $A$ of R751 aligning with $k l e C$ of RK2, which was expected from the relatedness of RK2 kle $A$ and kleC noted previously by Thomas et al. (1988). Comparison of kle $A$ from RK2 and R751 with $k l e C$ from RK2 as well as the predicted polypeptide products (RK2 KleA:R751 KleA, $68 \%$; RK2 KleA:RK2 KleC, $38 \%$; R751 KleA:RK2 $\mathrm{KleC}, 36 \%$ ) showed that the two kle $A$ genes are more closely related than either is with $k l e C$. Comparison of codon usage of conserved amino acids showed a much higher proportion of completely conserved codons between the two kle $A$ genes than with the kle $A-k l e C$ pairs. One would expect that if the higher degree of conservation were due to functional constraints then drift would have allowed greater divergence in the third position of the codons for conserved amino acids. This strongly suggests that the separation of kle $A$ and kleC preceded the separation of the $\alpha$ and $\beta$ kle $A$ genes. We therefore propose that this duplication was possessed by the common ancestor of the IncP plasmids, and that it has subsequently been lost by the IncP $\beta$ subfamily. A fourth nonconserved region is described in the next section.

\section{The klaAklaBklaC (kilAtelAtelB) region is completely absent from $\mathbf{R 7 5 1}$}

In RK2, the kor $A$ gene is preceded by an operon which is regulated by $\operatorname{Kor} A$ and $\operatorname{Kor} B$; the operon is associated with cryptic tellurite resistance and IncW plasmid fertility inhibition (Goncharoff et al., 1991; Walter et al., 1991; Yusoff \& Stanisich, 1984). This is completely absent from R751 (Fig. 2b), which is consistent with the lack of cryptic tellurite resistance (Bradley, 1985). Downstream of kleF, 
(a)

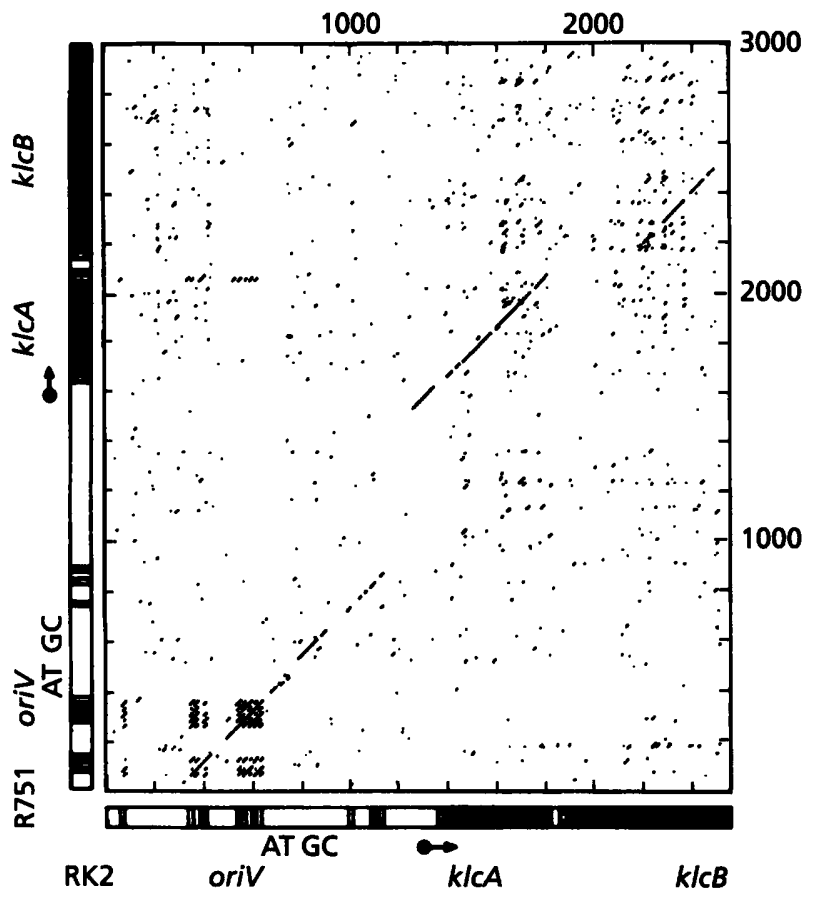

Fig. 2. Comparisons of the RK2 (horizontal axis) and R751 (vertical axis) oriv-korA segments. Dotplots were created using COMPARE with a window size of 20 and a stringency of 13. ORFs, solid blocks with open arrow heads; promoters, solid circles with arrow; terminators, $t$. The comparison was split into two based on the position of Tn1 insertion in KICB in RK2. (a) oriV-k/CB (Nterminal region) segment. Repeats in oriV region are shown as bars. Two of the degenerate repeats downstream of oriv (numbers 10, 11 and 12) are inverted (repeat 10 and 12) relative to the orientation of the repeats in oriV. (b) $k I C B$ (C-terminal region) to korA segment.

(b)

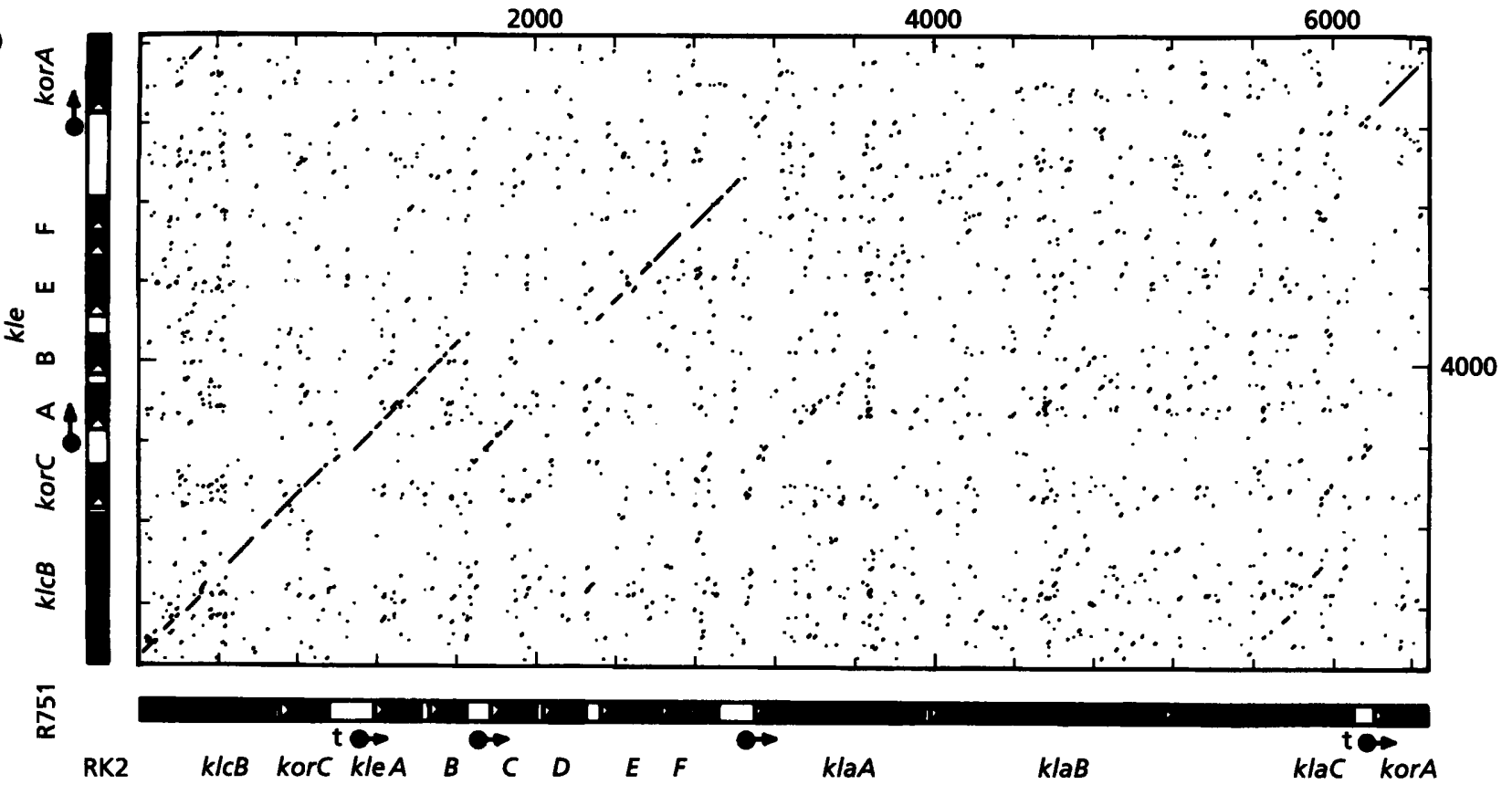

$\mathrm{RK} 2$ and $\mathrm{R} 751$ diverge so that there is no trace of the kla $A$ promoter/operator region. Sequence identity only returns about $300 \mathrm{bp}$ further on with respect to the R751 sequence, at the kor $A$ promoter/operator region (Fig. $3 a$ ). These genes therefore have either been deleted from R751 or gained by RK2. The degree of similarity between the kor $A$ and kil $A$ promoters of RK2 versus the degree of divergence between the kor $A$ promoters of RK2 and R751 (Fig. 4b) suggests that the two promoters must have arisen by a duplication event more recently than the divergence of the IncP $\alpha$ and $\operatorname{IncP} \beta$ subfamilies. However, there are also considerable similarities between $\operatorname{kor} A$ and $\operatorname{trf} A$ promoters within the IncP $\alpha$ subfamily despite the clear existence of both promoters in the common IncP ancestor, suggesting that selective pressure or gene conversion may maintain promoter similarities within a plasmid genome. This is borne out for the KorC-regulated promoters as described below. Therefore, we cannot make any deductions about whether the common ancestor contained the kla operon. However, we can conclude that the klaAklaBklaC operon is not essential for efficient survival of IncP plasmids. 
(a)

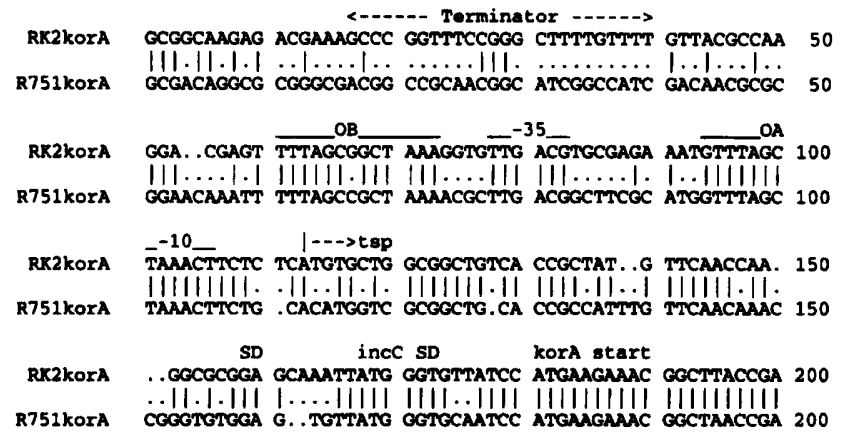

RK2kOYA AAGCCAGTTC CAGGAGGCGA TCCAGGGGCT GGAAGTGGGG CAGCAGACCA 250

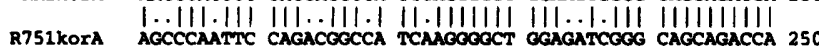

RK2kOYA TCGAGATAGC GCGGGGCGTC TTAGTCGATG GGAGCCACA GGCGACGTTC 300

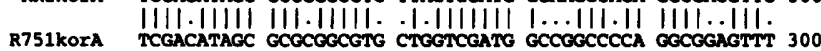

RK2korA GCMACGTCGC TGGGACTGAC CAGGGGCGCA GTGTCGCAAG CGGTGCATCG 350



R751kotA GTCACTTCGC TGGGGCTGAC CAAGGGGCCG GTGTCGCAGG COGTCAGTCG 350

RK2korA CGTGTGGGCC GCGTTCGAGG ACAMGAACTT GCCCGAGGGG TACGCGCGGG 400 R751kora CGTATGGGCa GCAGCAGGG aACAG...CT CCCCGAGGC TTCGAGCGAG 400

RK2korA tAACGGCGGT TCTGCCGGAA CATCAGGCGT ACATCGTCCG GAAGTGGGAA 450

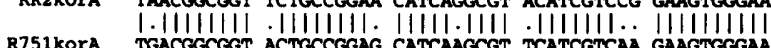
R751kora tGACGgCGgT ACTGCCGgAG CATCAAGCGT TCATCGTCAA GAAGTGGGAA 450

RK2kora GCGGACGCCA AGAAAAAACĀ SD- GGAACCAAA CGATGAAAC TTTGGTCACG 500 ince'start

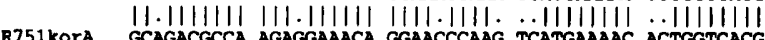

(b)

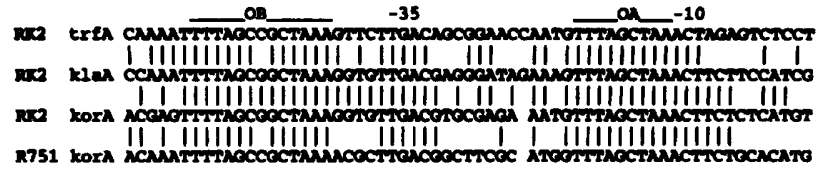

(c)

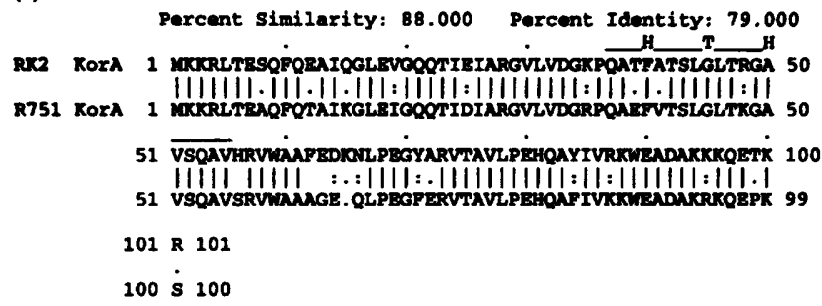

Fig. 3. Alignment of sequences from RK2 and R751. (a) korA DNA sequences; (b) KorA-regulated promoters in which $O_{A}$ overlaps the -10 region; and (c) KorA amino acid sequences. Solid lines indicate identity; colons indicate similarity. $O_{A}$ and $O_{B}$ sequences are the inverted repeats of the operators which mediate repression by KorA and KorB, respectively.

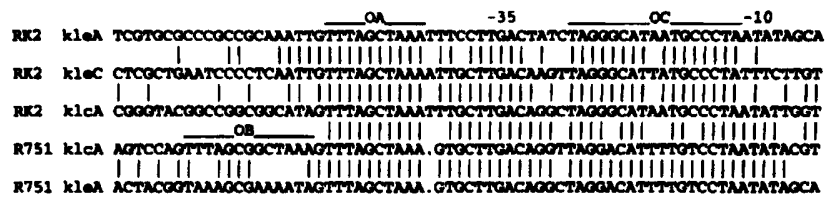

Fig. 4. Alignment of sequences of RK2 and R751 KorCregulated promoters. Solid lines indicate identity.
The gap between kleF and kor $A$ in $\mathrm{R} 751$ contains an additional ORF of 89 codons. We have tentatively called this $k l e G$, but we do not know whether it is expressed as a polypeptide. Database searches revealed no unambiguous similarities, but there was alignment with a variety of bacterial integrases, raising the intriguing possibility that in the IncP $\alpha$ ancestor this region could have promoted acquisition of a foreign DNA segment but may then have been lost in rearrangements to bring the new genes under the control of a promoter derived by duplication of the kor $A$ promoter.

\section{Conservation of oriV-related sequences}

We have previously reported that ori $V$ sequences diverge significantly (about 35\% mismatches) between RK2 and R751 (Smith \& Thomas, 1985). Fig. 2(a) shows a grid-like pattern due to alignment of the iterons to which TrfA binds (Pinkney et al., 1987; Kittell \& Helinski, 1991), which are repeated nine times in the RK2 oriV region and eight times in the $\mathrm{R} 751$ ori $V$ region (the ninth repeat in R751 is located on the other side of Tn4321). These repeats are followed by conserved $\mathrm{A}+\mathrm{T}$-and $\mathrm{G}+\mathrm{C}$-rich regions and then by a region in which we previously identified additional TrfA iterons in direct and in inverted orientation (Smith \& Thomas, 1985, 1989). Each of the sequence features shows conservation with RK2. A very closely related sequence also appears at the end of $k l c A$ (TGACTGATGAGGGC in R751 compared to $\mathrm{TGACA}^{\mathrm{G}} / \mathrm{C} / \mathrm{T}$ TGAGGGC in RK2 and R751 ori $V$ ), giving rise to the short repeated diagonals aligning between the end of kilC of R751 and oriV of RK2. The significance of these extra sites is not understood. It is possible that they modulate initiation negatively as proposed for the sites upstream of the minimal origin (Thomas et al., 1984). Alternatively, they may assist in the activation of the replication origin by forming a TrfAmediated loop as was proposed for RSF1010 (Haring \& Scherzinger, 1989).

It was previously found that the HaeII oriV was not able to promote the multiplication of an M13-derivative which was defective in the lagging-strand origin, implying that a primosome assembly site, if it exists, must lie further downstream (D. G. Guiney, personal communication). Unfortunately, the sequence alignments did not reveal an obvious candidate for such a lagging-strand origin or primosome assembly site outside the HaeII oriV fragment.

\section{Transcriptional terminators are not conserved}

In RK2 there are very strong putative rho-independent transcriptional terminators located upstream of kor $A$ (Thomas \& Smith, 1986) and kle $A(k c r A)$ (Thomas et al., 1988); these define the ends of kla $A B C$ and klc $A B k$ kor $C$ operons, respectively, and appear to protect the downstream operons from read-through transcription. Neither of these putative terminators is conserved in R751 and alternatives do not appear to exist. For kor $A p$, the next upstream promoter is only $1.3 \mathrm{~kb}$ away. This gap includes the highly conserved hairpin between kleB (kcr $A 2)$ and $k l e E$, but this is unlikely to be a transcriptional terminator. 




Fig. 5. Alignment of KlCA from RK2 and R751 and ArdB from pKM101.

kor $C$ is separated from the $\operatorname{klc} A$ promoter by about $2 \mathrm{~kb}$. In $\mathrm{RK} 2$, both regions which now contain terminators have additional DNA which is not present in R751. In the case of the klc AkorC operon the bla gene of $\operatorname{Tn} 1$ brought in a constitutive promoter firing towards korC and kle $A B C D$. It is possible that the unregulated transcription from this promoter provided the pressure to protect the kle operon from upstream transcription. In the case of the kor $A B F G$ operon the presence of the kla operon in RK2 is tightly regulated by KorA and KorB and should not therefore have caused a problem, providing no obvious explanation for the need for a terminator.

Within the kle transcript (between kleD and kleE in RK2 and between kleB and kleE in R751) there is a conserved inverted repeat which may modulate transcription by representing a pause during elongation or may modulate mRNA stability.

\section{Conservation and drift of korA}

Fig. 3 shows alignment of the RK2 and R751 kor $A$ genes (Fig. 3a) and predicted KorA proteins (Fig. 3c): at both the DNA and the polypeptide levels there is $79 \%$ identity. Many of the DNA changes affect only the degenerate third position of the kor $A$ codons. By contrast, the conservation of the overlapping inc C ORF is lower $(62 \%$ identity), suggesting that KorA has been under more constraint than this part of IncC. Similarly, coDonPREFERENCE identifies kor $A$ as the ORF which conforms to standard IncP codon usage. The proposed helixturn-helix motif in KorA is reasonably conserved, with four changes in the 21 amino acids of this region. Nevertheless, the sequence identified as the KorA operator is completely conserved between R751 and RK2 despite the high degree of divergence that has occurred between the two plasmids in this region. This suggests that any changes in KorA have not altered the basic operator recognition although they may have changed the strength of interaction. Outside the coding region the degree to which drift has occurred is quite remarkable (Fig. 3a). There is apparently no identity except in regions which should be functionally conserved, such as the -10 , $-35, \mathrm{O}_{\mathrm{A}}$ and $\mathrm{O}_{\mathrm{B}}$ regions, unless a number of gaps are introduced. This suggests that drift has occurred both by base deletion/insertion and by base substitution.

\section{Conservation and drift of korC}

The kor $C$ genes are also highly conserved. However the least conserved region is the proposed helix-turn-helix motif (Kornacki et al., 1990). Although there are only two KorC-regulated promoters in R751, it is interesting to note that the putative KorC operators are identical to each other but different by two bases from the RK2 KorC operators (Fig. 5). These changes are symmetrical and preserve the perfect inverted-repeat structure. The changed operator sequence may correlate with the changes in the KorC protein. This identity of KorC operators within each plasmid subfamily suggests that there is strong selective pressure to maintain similar repressoroperator interactions at all regulatory points on a single genome. Gene conversion may provide the means to transfer any mutational changes from one control region to another.

\section{The klc operon of R751}

It has been proposed that the ancestral IncP plasmid contained an operon consisting of $k l c A(k i l C), k l c B$ (prekorC or ORFX) and korC (Thomas et al., 1988; Larsen \& Figurski, 1994). R751 appears to contain this operon intact. The high degree of conservation of the klc $A$ ORF suggests that it still plays an important role in the survival of these plasmids (Fig. 6). It has been noted (Larsen \& Figurski, 1994) that KlcA shows $31 \%$ sequence identity with the ArdB protein of the IncN plasmid pKM101 (Belogurov et al., 1993), suggesting that KlcA may form part of an antirestriction system which could help RK2 to overcome restriction barriers during establishment after conjugative transfer. Fig. 5 includes the ArdB protein in the alignment of KlcA proteins. The degree of identity with the R751 KlcA (32\%) is very similar to that with RK2 KlcA. It is clear that the regions of identity with ArdB lie within the regions of highest identity between the two KlcA proteins, which is consistent with the idea that the sequence conservation represents selection for maintenance of a common structure or function. However, the motif that Belogurov et al. (1993) found to be conserved between different antirestriction proteins (ColIb Ard, pKM101 ArdA, pKM101 ArdB and T7 0.3 gene product), LLREYVNTL in ArdB, termed the Ard Box, is not conserved between ArdB and the IncP proteins. Nor is the equivalent region conserved between the IncP proteins themselves.

Immediately after the end of $k l c A$, the plasmids diverge quite dramatically. However, in both plasmids a second ORF preceded by a Shine-Dalgarno sequence follows the klc $A$ ORF with a $\mathrm{G}+\mathrm{C}$-rich hairpin lying between the two. The predicted products of the ORFs show $56.5 \%$ 
(a)

Percent Similarity: 70.637 Percent Identity: 56.510

RK2 K1CB 51 PLPTCCVLDGLKFCDDYRKPDCIAAYLVANPTPPEATTPAARRRTKARKS 100

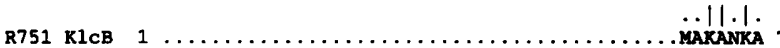

$101 \mathrm{~K}$. PQTEDKDARIAALAATLPEDRAGLLAVAADAVAAVHDAVLNRADLVAD 149

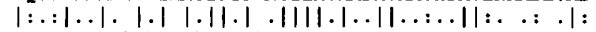
8 TGPDGQDWSAPAAELLAEL PADCDGLLAAAVAAVVEIDAAVMRGDGAAE 57

150 VAGERYAAAVWKLNGGTFFGCAGDQDAAERVIERHCRATPGVVPWGQDX 199 58 LAGDRYEAI IWKLWGGTWFGCMADDEAAGRVIERHCAAVPGDVPLWGQRG 107

200 DFLASVDGMRUWVEVESGYGGLTVHFOFHAVDLDGPFISETGYRSHYDH 249 $: \|||$.:::|.:|| |.|||| ..||||||||||| ||||.||||||:| 108 QFLAVAGDVRALVEYEAGYGGPLNAHFQFHAVDLDRPFISATGYRSHFDT 157

250 ARGGMTVDQVADGVLRALLRSSHRR. ,YLDARDQDRLADEPLPAWLAGITP 297

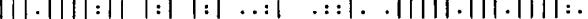
158 ARGCMTVDEVARGILTAMLAEKKRPVLIEANYRDRLADAPLPDWLAGLVP 207

298 PPRRVRAVVEDWRKPDELPPGFAWVDAVLPAHQAFIARKWAASAKAKLAA 347 208 PARREPATV. ...... TIPPGFVLVDVVLPAHKAFIARRGAAEAAGKVKA 250

348 ARAK. . AQEPAGQRREPVTPAKPEPEPAKDEDAPAWPATFF. . . . PGLR 390

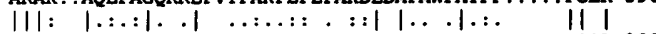
251 ARARSNAKGKPGASEIRIGGNGALQHRQEMACQARADLVEFTPAPGQR 300

391 CEIVSVHHPVFAKEIGKHVIITKISPETRQWWAHDDKPPRYRINRNGRKV 440

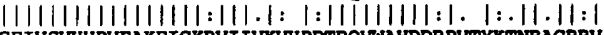
301 CEIVSVHHPVFAKEIGKRVIIVKVHPDTRQVWAHDDRPVTYKTNRAGRRV 350

441 CEYDPRCIESCYGYDQLRAAI 461

$\therefore|| .||:||.|:||| \mid$

351 VDSDPSCIOSIYGFDOLRLIT 372

(b)

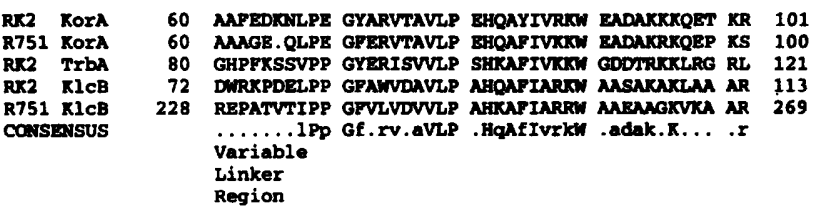

Fig. 6. (a) Alignment of KICB from RK2 and R751. (b) Alignment of domains conserved between KorA, TrbA and KIcB.

identity but diverge to the greatest extent at their $\mathrm{N}$ termini. It is possible that this drift is due to the loss of selection on RK $2 k l c B$ after its inactivation by the insertion of $\mathrm{Tn} 1$. However, the retention of an intact ORF does not support this idea.

\section{A conserved domain in $k / c B$}

Sequence comparisons revealed a region in the klcB ORF preceding $k$ or $C$ which had strong similarity to the Cterminal domains of KorA and TrbA (Fig. 6; Thomas reported in Pansegrau et al., 1994; Larsen \& Figurski, 1994). Our sequence comparisons have shown quite clearly that this region is likely to form a separate domain joined to the DNA-binding domain by a short variable region (G. Jagura-Burdzy \& C. M. Thomas, unpublished results). The segment in $\mathrm{KlcB}$ covers the whole of this putative 35 amino acid domain. In addition, it may be significant that an insertion of seven amino acids in RK2 which is not present in R751 occurs precisely in the proposed variable region, strengthening the idea that this is a linker region between two domains and so can tolerate considerable modification.

\section{R751 has an extra KorB binding site upstream of $\boldsymbol{k I C A}$}

The location, organization and spacing of regulatory sequences are almost identical between the two plasmids. KorA operators are located upstream of -35 regions for $k l e A p$ and $k l c A p$ and overlapping the -10 for kor $A p$. Putative KorC operators overlap -10 regions for kle $A p$ and $\operatorname{klc} A p$. A KorB operator is found downstream of $\operatorname{kor} C$ in both plasmids, although it is unclear whether binding of KorB in this region plays a role in regulating either korC or kle $A$.

The only difference between the two plasmids is in the presence of an extra KorB operator directly upstream of the KorA operator in the $\operatorname{klc} A$ promoter. We would expect KorB to bind to this site but the spacing between the KorB and KorA operators is much closer here than observed elsewhere. The possibility that binding of these two regulatory proteins is mutually exclusive at these sites should be investigated since this may represent a novel aspect of modulation of gene expression by products of the central control operon.

\section{Conservation of other proteins}

The other conserved ORFs encode $\mathrm{KleA}, \mathrm{KleB}, \mathrm{KleE}$ and $\mathrm{KleF}$. The degree of sequence identity varies from $53 \%$ (KleB) to $68 \%(\mathrm{KleA})$. Comparison to proteins in the databases with known activities have failed to identify likely functions for these gene products. KleA has a high predicted level of $\alpha$-helical content and a rather regular arrangement of hydrophobic residues interspersed with hydrophilic residues, which could suggest the formation of a coiled-coil structure. However, this feature is less obvious in R751 than it is in RK2. KleB shows a helixturn-helix motif. This is flanked by four conserved cysteines with a spacing which aligns well with a variety of zinc-finger motifs. These cysteines could coordinate to $\mathrm{Zn}^{2+}$ to provide a means of holding the helix-turn-helix motif rigid as an alternative to a larger protein scaffold to which helix-turn-helix motifs are normally attached. Although the gene regulation phenotype, $\mathrm{KorE}^{+}$, is associated with this region, the mapping carried out by Kornacki et al. (1993) is not consistent with the KleB protein being responsible for this phenotype. Neither $\mathrm{KleE}$ nor $\mathrm{KleF}$ display features which clearly indicate structure or function. KleG shows about $30 \%$ identity with an internal segment of a fusaric acid resistance protein from Pseudomonas cepacia as well as low-level similarity to a variety of integrases.

\section{Concluding remarks}

The sequence comparisons described in this paper allow us to define more closely the IncP backbone which is conserved between $\alpha$ and $\beta$ subfamilies. This provides a simpler picture than is presented by the IncP $\alpha$ plasmids alone. Studies on other regions of the plasmids have assigned many of the genes which are co-regulated by the central control operon to specific functions such as replication, transfer and stability (Shingler et al., 1984a, b; Smith et al., 1984; Motallebi-Veshareh et al., 1990, 1992; 

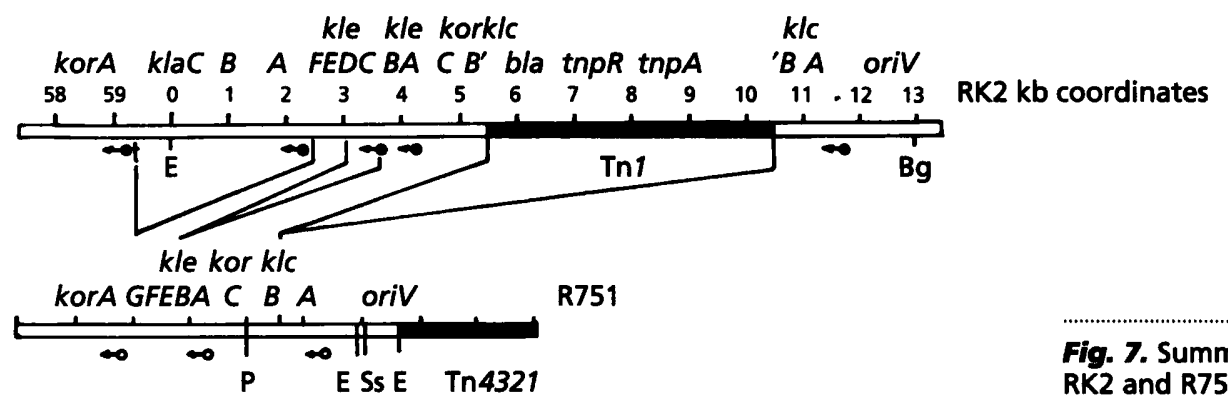

Fig. 7. Summary of the comparison between RK2 and R751 in the korA-oriV region.

Thomson et al., 1993). This left the kor $A$-oriV region with the largest number of unassigned genes. The combination of the comparison described here (summarized in Fig. 7), which shows that only the klc and kle operons belong to the conserved core, and the suggestion by Larsen \& Figurski (1994) that the klc operon may provide an antirestriction system, reduces the number of apparently redundant genes. We hope that this comparison will aid future work to focus on the most important genes and the conserved motifs within these genes, as well as helping to simplify the picture of these uniquely integrated plasmid genomes.

\section{ACKNOWLEDGEMENTS}

We thank Grazyna Jagura-Burdzy and Peter Thorsted for help in preparing this manuscript. This work was supported by MRC project grants G8224213CB, G8309838CB and G919550CB awarded to C.M.T. Project students involved in various stages of this work were Zaid Marham, Jane Birch and Allison Williams. L. J. was supported by a studentship from the Northern Ireland Education Authority. N.W. was supported by a Chinese Government Scholarship. Oligonucleotides were synthesized by AltaBioscience, University of Birmingham. Some autoradiography was carried out with a Molecular Dynamics Phosphorimager purchased with shared equipment grants from the Wellcome Trust (037160) and the Medical Research Council (G9216078MB). Some of the sequencing was performed on an ABI Automated Sequencer, run by AltaBioscience and purchased with a shared equipment grant from the Wellcome Trust (038654).

\section{REFERENCES}

Balzer, Z., Ziegelin, G., Pansegrau, W., Kruft, V. \& Lanka, E. (1992). KorB protein of promiscuous plasmid RP4 recognizes inverted sequence repetitions in regions essential for conjugative transfer. Nucleic Acids Res 20, 1851-1858.

Belogurov, A. A., Delver, E. P. \& Rodzevich, O. G. (1993). Plasmid pKM101 encodes two nonhomologous antirestriction proteins (ArdA and ArdB) whose expression is controlled by homologous regulatory sequences. $J$ Bacteriol 175, 4843-4850.

Birnboim, H. C. \& Doly, J. (1979). A rapid alkaline extraction procedure for screening recombinant plasmid DNA. Nucleic Acids Res 7, 1513-1523.

Bradley, D. (1985). Detection of tellurite-resistance determinants in IncP plasmids. J Gen Microbiol 131, 3135-3137.

Chikami, G. K., Guiney, D. G., Schmidhauser, T. J. \& Helinski, D. R. (1985). Comparison of ten IncP plasmids: homology in the regions involved in plasmid replication. J Bacteriol 162, 656-660.
Devereux, J., Haeberli, P. \& Smithies, O. (1984). A comprehensive set of sequence analysis programs for the VAX. Nucleic Acids Res 12, 387-395.

Figurski, D. H \& Helinski, D. R. (1979). Replication of an origin containing derivative of plasmid RK2 dependent on a plasmid function provided in trans. Proc Natl Acad Sci US A 79, 1935-1939.

Figurski, D. H., Pohlman, R. F., Bechhofer, D. H., Prince, A. S. \& Kelton, C. A. (1982). The broad-host-range plasmid RK2 encodes multiple kil genes potentially lethal to Escherichia coli host cells. Proc Natl Acad Sci USA 79, 1935-1939.

Furste, J. P., Pansegrau, W., Ziegelin, G., Kroger, M. \& Lanka, E. (1989). Conjugative transfer of promiscuous IncP plasmids: interaction of plasmid-encoded products with the transfer origin. Proc Natl Acad Sci US A 86, 1771-1775.

Goncharoff, P., Saadi, S., Chang, C. H., Saltman, L. H. \& Figurski, D. H. (1991). Structural, molecular, and genetic analysis of the kil $A$ operon of broad-host-range plasmid RK2. J Bacteriol 173, $3463-3477$.

Guiney, D. G. \& Helinski, D. R. (1979). The DNA-protein relaxation complex of the plasmid RK2: location of the site-specific nick in the region of the proposed origin of transfer. Mol \& Gen Genet 176, 183-189.

Guiney, D. G. \& Jakobson, E. (1983). Location and nucleotide sequence of the transfer origin of the broad host range plasmid RK2. Proc Natl Acad Sci US A 80, 3595-3598.

Guiney, D. G. \& Lanka, E. (1989). Conjugative transfer of IncP plasmids. In Promiscuous Plasmids of Gram-negative Bacteria, pp. 27-54. Edited by C. M. Thomas. London: Academic Press.

Guiney, D. G., Deiss, C., Simnad, V., Yee, L., Pansegrau, W. \& Lanka, E. (1989). Mutagenesis of the Tra1 core region of RK2 by using $\operatorname{Tn} 5$ : identification of plasmid-specific transfer genes. $J$ Bacteriol 171, 4100-4103.

Harayama, S., Tsuda, M., lino, T. (1980). High frequency mobilization of the chromosome of Escherichia coli by a mutant of RP4, temperature sensitive for maintenance. Mol \& Gen Genet 180, 47-56.

Haring, V. \& Scherzinger, E. (1989). Replication proteins of the IncQ plasmid RSF1010. In Promiscuous Plasmids of Gram-negative Bacteria, pp. 95-124. Edited by C. M. Thomas. London: Academic Press.

Jagura-Burdzy, G. \& Thomas, C. M. (1994). KorA protein of promiscuous plasmid RK2 controls a transcriptional switch between divergent operons for plasmid replication and conjugative transfer. Proc Natl Acad Sci US A 92, 10571-10575.

Jobanputra, R. S. \& Datta, N. (1974). Trimethoprim R-factors in enterobacteria from clinical specimens. J Med Microbiol 7, 169-177. Jovanovic, O. S., Ayres, E. K. \& Figurski, D. H. (1994). Hostinhibitory functions encoded by promiscuous plasmids: transient arrest of Escherichia coli segregants that fail to inherit plasmid RK2. $J$ Mol Biol 237, 52-64. 
Kittell, B. \& Helinski, D. R. (1991). Iteron inhibition of plasmid RK2 replication in vitro: evidence for intermolecular coupling of replication origins as a mechanism for replication control. Proc Natl Acad Sci US A 88, 1389-1393.

Kornacki, J. A., Burlage, R. S. \& Figurski, D. H. (1990). The kil-kor regulon of broad-host-range plasmid RK2: nucleotide sequence, polypeptide product and expression of regulatory gene korC. $J$ Bacteriol 172, 3040-3050.

Kornacki, J. A., Chang, C.-H. \& Figurski, D. H. (1993). kil-kor regulon of promiscuous plasmid RK2: structure, products, and regulation of two operons that constitute the kilE locus. J Bacteriol 175, 5078-5090.

Lanka, E., Furste, J. P., Yakobsen, E. \& Guiney, D. G. (1985). Conserved regions at the DNA primase locus of the $\operatorname{IncP} \alpha$ and IncP $\beta$ plasmids. Plasmid 14, 217-223.

Larsen, M. H. \& Figurski, D. H. (1994). Structure, expression and regulation of the kilC operon of promiscuous plasmid $\mathrm{IncP} \alpha$ plasmids. J Bacteriol 176, 5022-5032.

Lessl, M., Balzer, D., Lurz, R., Waters, V. L., Guiney, D. G. \& Lanka, E. (1992). Dissection of IncP conjugative transfer; definition of the transfer region Tra2 by mobilization of the Tra1 region in trans. $J$ Bacteriol 174, 2493-2500.

Lessl, M., Balzer, D., Weyrauch, K. \& Lanka, E. (1993). The mating pair formation system of plasmid RP4 defined by RSF1010 mobilization and donor-specific phage propagation. J Bacteriol 175, 6415-6425.

Maniatis, T., Fritsch, E. F. \& Sambrook, J. (1982). Molecular Cloning: a Laboratory Manual, 2nd edn. Cold Spring Harbor, NY: Cold Spring Harbor Laboratory.

Maxam, A. \& Gilbert, W. (1980). Sequencing end-labelled DNA with base-specific cleavage. Methods Enzymol 65, 449-560.

Meyer, R. J \& Shapiro, J. (1980). Genetic organization of the IncP1 plasmid R751. J Bacteriol 143, 1362-1373.

Miele, L., Strack, B., Kruft, V. \& Lanka, E. (1991). Gene organization and nucleotide sequence of the primase region of IncP plasmids RP4 and R751. DNA Seq 2, 145-162.

Motallebi-Veshareh, M., Balzer, D., Lanka, E., Jagura-Burdzy, G. \& Thomas, C. M. (1992). Conjugative transfer functions of broad host range plasmid RK2 are coregulated with vegetative replication. Mol Microbiol 6, 907-920.

Pansegrau, W. \& Lanka, E. (1987). Conservation of a common 'backbone' in the genetic organization of the IncP plasmids RP4 and R751. Nucleic Acids Res 19, 3455.

Pansegrau, W., Balzer, D., Kruft, V., Lurz, V. \& Lanka, E. (1990). In vitro assembly of relaxosomes at the transfer origin of plasmid RP4. Proc Natl Acad Sci US A 87, 6555-6559.

Pansegrau, W., Lanka, E., Barth, P. T., Figurski, D. H., Guiney, D. G., Haas, D., Helinski, D. R., Schwab, H., Stanisich, V. A. \& Thomas, C. M. (1994). Complete nucleotide sequence of Birmingham IncP $\alpha$ plasmids. Compilation and comparative analysis. $J$ Mol Biol 239, 623-663.

Sanger, F., Nicklen, S. \& Coulson, A. R. (1977). DNA sequencing with chain-terminating inhibitors. Proc Natl Acad Sci USA 74, 5463-5467.

Schreiner, H. C., Bechhofer, D. H., Pohlman, R. F., Young, C., Borden, P. A. \& Figurski, D. H. (1985). Replication control in promiscuous plasmid RK2: kil and kor functions affect expression of the essential replication gene $\operatorname{trf} A . J$ Bacteriol 163, 228-237.

Shingler, V. \& Thomas, C. M. (1984a). Analysis of the $\operatorname{trf} A$ region of broad host range plasmid RK2 by transposon mutagenesis and identification of polypeptides. J Mol Biol 175, 229-250.
Shingler, V. \& Thomas, C. M. (1984b). Transcription in the $\operatorname{trf} A$ region of broad host range plasmid RK2 is regulated by $\operatorname{trf} B$ and korB. Mol \& Gen Genet 195, 523-529.

Smith, C. A. \& Thomas, C. M. T. (1983). Deletion mapping of kil and kor functions in the $\operatorname{trf} A$ and $\operatorname{trf} B$ regions of broad host range plasmid RK2. Mol \& Gen Genet 190, 245-254.

Smith, C. A. \& Thomas, C. M. (1984). Nucleotide sequence of the $\operatorname{trf} A$ gene of the broad host range plasmid RK2. J Mol Biol 175, 251-262.

Smith, C. A. \& Thomas, C. M. (1985). Comparison of the nucleotide sequences of the vegetative replication origins of broad host range IncP plasmids R751 and RK2 reveals conserved features of probable functional importance. Nucleic Acids Res 13, 557-572.

Smith, C. A. \& Thomas, C. M. (1987). Comparison of the organization of the genomes of phenotypically diverse plasmids of incompatibility group $\mathrm{P}$ : members of the IncP $\beta$ subgroup are closely related. Mol \& Gen Genet 206, 419-427.

Smith, C. A. \& Thomas, C. M. (1989). Relationships and evolution of IncP plasmids. In Promiscuous Plasmids of Gram-negative Bacteria, pp. 57-77. Edited by C. M. Thomas. London: Academic Press.

Smith, C. A., Shingler, V. \& Thomas, C. M. (1984). The $\operatorname{trf} A$ and $\operatorname{trf} B$ promoter regions of broad host range plasmid RK2 share common potential regulatory sequences. Nucleic Acids Res 12, 3619-3630.

Smith, C. A., Pinkney, M., Guiney, D. G. \& Thomas, C. M. (1993). The ancestral IncP replication system consisted of contiguous oriV and $\operatorname{trf} A$ segments as deduced from a comparison of the nucleotide sequences of diverse IncP plasmids. J Gen Microbiol 139, 1761-1766.

Stalker, D. M., Thomas, C. M. \& Helinski, D. R. (1981). Nucleotide sequence of the origin of replication of the broad host range plasmid RK2. Mol \& Gen Genet 181, 8-12.

Theophilus, B. D. M., Cross, M. A., Smith, C. A. \& Thomas, C. M. (1985). Regulation of the $\operatorname{trf} A$ and $\operatorname{trfB}$ promoters of broad host range plasmid RK2: identification of sequences essential for regulation by $\operatorname{trfB} /$ kor $A /$ korD. Nucleic Acids Res 13, 8129-8142.

Thomas, C. M. \& Helinski, D. R (1989). Vegetative replication and stable inheritance of IncP plasmids. In Promiscuous Plasmids of Gramnegative Bacteria, pp. 1-25. Edited by C. M. Thomas. London: Academic Press.

Thomas, C. M. \& Smith, C. A. (1986). The $\operatorname{trfB}$ region of broad host range plasmid RK2: the nucleotide sequence reveals inc $C$ and key regulatory gene $\operatorname{trf} B /$ kor $A /$ kor $D$ as overlapping genes. Nucleic Acids Res 14, 4453-4467.

Thomas, C. M. \& Smith, C. A. (1987). Incompatibility group P plasmids: genetics, evolution and use in genetic manipulation. Annu Rev Microbiol 41, 77-101.

Thomas, C. M., Meyer, R. J. \& Helinski, D. R. (1980). Regions of the broad host range plasmid RK2 which are essential for replication and maintenance. $J$ Bacteriol 141, 213-222.

Thomas, C. M., Cross, M. A., Hussain, A. A. K. \& Smith, C. A. (1984). Analysis of the copy number control elements in the region of the vegetative replication origin of broad host range plasmid RK2. EMBO J 3, 57-63.

Thomas, C. M., Ibbotson, J. P., Wang, N., Smith, C. A., Tipping, R. \& Loader, N. M. (1988). Gene regulation on broad host range plasmid RK2: identification of three novel operons whose transcription is repressed by both KorA and KorC. Nucleic Acids Res 12, 5345-5359.

Thomas, C. M., Theophilus, B. D. M., Johnston, L., Jagura-Burdzy, G., Schilf, W. \& Lanka E. (1990). Identification of a seventh operon 
on plasmid RK2 regulated by the korA gene product. Gene 89, 29-35.

Thomson, V. J., Jovanovic, O. S., Pohlman, R. F., Chang, C.-H. \& Figurski, D. H. (1993). Structure, function and regulation of the kilB locus of promiscuous plasmid RK2. J Bacteriol 175, 2423-2435.

Vieira, J. \& Messing, J. (1982). The pUC plasmids, an M13 mp7derived system for insertion mutagenesis and sequencing with synthetic universal primers. Gene 19, 259-268.

Villaroel, R., Hedges, R. W., Maenhaut, R., Leemans, J., Engler, G., Van Montagu, M. \& Schell, J. (1983). Heteroduplex analysis of P-plasmid evolution: the role of insertion and deletion of transposable elements. Mol \& Gen Genet 189, 390-399.

Walter, E. G., Thomas, C. M., Ibbotson, J. P. \& Taylor, D. (1991). Transcriptional analysis, translational analysis, and sequence of the kil $A$-tellurite resistance region of plasmid $\mathrm{RK} 2 \mathrm{Te}^{\mathbf{R}}$. J Bacteriol 173, 1111-1119.

Waters, V. L., Strack, B., Pansegrau, W., Lanka, E. \& Guiney, D. G. (1992). Mutational analysis of essential IncP $\alpha$ plasmid tansfer genes traF and tra $G$ and involvement of $t r a F$ in phage sensitivity. J Bacteriol 174, 7486-7489.

Williams, D. R., Motallebi-Veshareh, M. \& Thomas, C. M. (1993). Multifunctional repressor KorB can block transcription by pre- venting isomerization of RNA polymerase-promoter complexes. Nucleic Acids Res 21, 1141-1148.

Yakobson, E. \& Guiney, D. (1983). Homology in the transfer origins of broad-host-range IncP plasmids: definition of two subgroups of P-plasmids. Mol \& Gen Genet 192, 436-438.

Young, C., Prince, A. S. \& Figurski, D. H. (1985). kor $A$ function of promiscuous plasmid RK2: an autorepressor that inhibits expression of host-lethal gene kil $A$ and replication gene $\operatorname{trf} A$. Proc Natl Acad Sci US A 82, 7374-7378.

Young, C., Burlage, R. S. \& Figurski, D. H. (1987). Control of the kil $A$ gene of broad-host-range plasmid RK2: involvement of kor $A$, korB and a new gene korE. J Bacteriol 169, 1315-1320.

Yusoff, K. \& Stanisich, V. (1984). Location of a function on RP1 that fertility inhibits IncW plasmids. Plasmid 11, 178-181.

Ziegelin, G., Pansegrau, W., Strack, B., Balzer, D., Kroger, M., Kruft, V. \& Lanka, E. (1991). Nucleotide sequence and organization of genes flanking the transfer origin of promiscuous plasmid RP4. $D N A S_{e q}$ 1, 303-327.

Received 20 October 1994; revised 9 January 1995; accepted 18 January 1995. 